\title{
GATA3 immunoreactivity expands the transcription factor profile of pituitary neuroendocrine tumors
}

\author{
Ozgur Mete ${ }^{1} \cdot$ Mehmet Kefeli $^{2} \cdot$ Sultan Çalışkan² ${ }^{2}$ Sylvia L. Asa $\mathbb{i}^{1}$
}

Received: 24 August 2018 / Revised: 1 October 2018 / Accepted: 2 October 2018 / Published online: 2 November 2018

(c) United States \& Canadian Academy of Pathology 2018

\begin{abstract}
The modern classification of pituitary neuroendocrine tumors relies mainly on immunohistochemistry for pituitary transcription factors, hormones, and other biomarkers, including low molecular weight cytokeratins. The transcription factor GATA2 is required for development of gonadotrophs and thyrotrophs but has not been used for classification of pituitary tumors. Because of genomic paralogy of GATA2 and GATA3, we postulated that GATA3 immunohistochemistry may detect GATA2 in the adenohypophysis. We examined 151 tumors originating from Ondokuz Mayis University, Turkey $(n=$ 83 ) and University Health Network, Canada $(n=68)$. Initially, 83 tumors (26 gonadotroph, 24 somatotroph, 17 corticotroph, 12 lactotroph, 2 poorly differentiated Pit-1 lineage tumors that expressed TSH and 2 null cell tumors) from Ondokuz Mayis University were investigated with the GATA3 monoclonal antibody L50-823. Retrospective review of the files of University Health Network identified 68 tumors (43 gonadotroph, 3 somatotroph, 2 lactotroph, 1 mammosomatotroph, 9 corticotroph, 7 poorly differentiated Pit-1 lineage tumors with TSH expression, 2 plurihormonal tumors with TSH expression and 1 null cell tumor) that were examined with the same GATA3 antibody and served as a validation cohort. All somatotroph, lactotroph and mammosomatotroph tumors and the null cell tumors were negative for GATA3. Sixty-eight (98.5\%) gonadotroph tumors were positive for GATA3; 64 had diffuse reactivity. Two plurihormonal tumors with TSH expression and eight (88.8\%) poorly differentiated Pit-1 lineage tumors with variable TSH expression were positive for GATA3. One of 26 (3.8\%) corticotroph tumors was diffusely positive for GATA3. This study shows that GATA3 immunoreactivity is characteristic of pituitary gonadotroph and TSH-producing tumors. This finding expands the pattern of transcription factors that are used to classify adenohypophysial tumors and is important in the differential diagnosis of sellar tumors, as GATA3 expression is also a feature of primary sellar paragangliomas as well as carcinomas that may metastasize to the sella.
\end{abstract}

\section{Introduction}

The classification of pituitary cells and pituitary neuroendocrine tumors [1] has evolved with the identification of transcription factors that play a role in adenohypophysial cell differentiation. Initial progress was made when the

Ozgur Mete

ozgur.mete2@uhn.ca

$\triangle$ Sylvia L. Asa

sylvia.asa@utoronto.ca

1 Department of Pathology, University Health Network, and Department of Laboratory Medicine and Pathobiology, University of Toronto, Toronto, Canada

2 Department of Pathology, Ondokuz Mayis University, Samsun, Turkey pituitary transcription factor-1 (Pit-1) was identified and found to regulate expression of the growth hormone $(\mathrm{GH})$ and prolactin (PRL) genes [2-5]; subsequent studies identified a role for Pit-1 in regulation of the beta-thyrotropin (thyroid stimulating hormone, TSH) gene [6, 7]. Similarly, the transcription factor steroidogenic factor-1 (SF-1) was implicated in pituitary gonadotroph development and function in addition to its critical role in steroidogenic tissues $[8,9]$. These biomarkers provided reliable identification of pituitary tumor cytogenesis $[10,11]$ and paved the way for a more reliable classification of adenohypophysial tumors $[12,13]$, while also explaining the frequent plurihormonality of tumors of Pit-1 lineage. The discovery of Tpit as the nuclear driver of corticotroph tumors $[14,15]$ provided the nuclear hallmark of the trilineage pattern of adenohypophysial development and tumorigenesis [16].

The common expression of alpha-subunit by both thyrotrophs and gonadotrophs as well as somatotrophs has been 
Table 1 Summary of GATA3 expression profile in pituitary neuroendocrine tumors: discovery and validation series

\begin{tabular}{|c|c|c|c|}
\hline & $\begin{array}{l}\text { GATA3 negative } \\
(n)\end{array}$ & $\begin{array}{l}\text { GATA3 focally } \\
\text { positive }(n)\end{array}$ & $\begin{array}{l}\text { GATA3 diffusely } \\
\text { positive }(n)\end{array}$ \\
\hline \multicolumn{4}{|l|}{ Discovery series ( $n: 83$ ) } \\
\hline Gonadotroph tumors $(n: 26)$ & 0 & 0 & 26 \\
\hline Somatotroph tumors $(n: 24)$ & 24 & 0 & 0 \\
\hline Lactotroph tumors $(n: 12)$ & 12 & 0 & 0 \\
\hline $\begin{array}{l}\text { Poorly differentiated Pit-1 lineage tumor } \\
(n: 2)\end{array}$ & 0 & 2 & 0 \\
\hline Corticotroph tumors $(n: 17)$ & 17 & 0 & 0 \\
\hline Null cell tumors $(n: 2)$ & 2 & 0 & 0 \\
\hline \multicolumn{4}{|l|}{ Validation series (n:68) } \\
\hline Gonadotroph tumors $(n: 43)$ & 1 & 4 & 38 \\
\hline Somatotroph tumors $(n: 3)$ & 3 & 0 & 0 \\
\hline Mammosomatotroph tumors $(n: 1)$ & 1 & 0 & 0 \\
\hline Lactotroph tumors $(n: 2)$ & 2 & 0 & 0 \\
\hline $\begin{array}{l}\text { Poorly differentiated Pit-1 lineage tumor } \\
(n: 7)\end{array}$ & 1 & 3 & 3 \\
\hline Corticotroph tumors $(n: 9)$ & 8 & 0 & 1 \\
\hline $\begin{array}{l}\text { Plurihormonal tumor with beta-TSH } \\
\text { expression }(n: 2)\end{array}$ & 0 & 2 & 0 \\
\hline Null cell tumors $(n: 1)$ & 1 & 0 & 0 \\
\hline
\end{tabular}

ascribed to activation of cyclic AMP pathways. However, another transcription factor implicated in the development and function of both cell lineages that produce glycoprotein hormones, thyrotrophs, and gonadotrophs, is GATA2 $[9,17]$. To date, there has been limited application of this information to the diagnosis of pituitary tumors [18].

Because of the genomic paralogy of GATA2 and GATA3 [19], and the widespread use of antibodies to GATA3 in human pathology [20-25], we hypothesized that application of GATA3 immunohistochemistry may play a role in the accurate classification of pituitary neuroendocrine tumors. Moreover, the expression of GATA3 could potentially lead to misdiagnosis in the case of metastatic tumors to the pituitary as well as in the setting of sellar paragangliomas.

\section{Materials and methods}

A total of 151 adenohypophysial tumors originating from the Ondokuz Mayis University, Turkey $(n=83)$ and University Health Network, Canada $(n=68)$ were included in this study. Institutional Research Ethics Board approvals were obtained from both institutions.

The initial series was composed of 83 tumors diagnosed at the Ondokuz Mayis University. These included 26 gonadotroph, 24 somatotroph, 17 corticotroph, 12 lactotroph, 2 poorly differentiated plurihormonal Pit-1 lineage tumors that expressed beta-TSH, and 2 null cell tumors.
Subsequently, a retrospective review of the files of University Health Network identified 68 adenohypophysial tumors that had been stained for GATA3 and served as the validation cohort for this study. These included 43 gonadotroph, 3 somatotroph, 2 lactotroph (including one acidophil stem cell), 1 mammosomatotroph, 9 corticotroph, 7 poorly differentiated plurihormonal Pit-1 lineage tumors with variable beta-TSH expression, 2 plurihormonal tumors with focal beta-TSH expression and 1 null cell tumor.

All tumors were investigated with a monoclonal antibody to GATA3 (Clone L50-823) using a Benchmark XT automated stainer (Ventana Medical Systems, Inc. Tucson, AZ). The L50-823 monoclonal antibody was raised against peptide between the trans-activation and DNA-binding domains of GATA3. The GATA proteins have highly conserved sequences in their binding domains, the type IV zinc fingers, referred to as $\mathrm{N}$-finger (N-terminal zinc finger) and C-finger (C-terminal zinc finger). The sequences immediately following the two zinc fingers are also conserved, whereas other sequence motifs, such as the putative trans-activation domains including the region used to create this antibody, are less conserved in the GATA family [26, 27]. Because, GATA2 and GATA3 are highly homologous in the region identified by this antibody, the results that we report may represent expression of GATA3 or may represent cross-reactivity of GATA2.

GATA3 nuclear reactivity was recorded as positive when $\geq 5 \%$ of the cells were positive. Positivity for GATA3 was recorded as focal or diffuse. 


\section{Results}

The results of both series are summarized in Table 1. All somatotroph $(n=28)$ and lactotroph $(n=14)$ tumors, the mammosomatotroph tumor, and the null cell tumors $(n=3)$ lacked reactivity for GATA3.

Sixty-eight of $69(98.5 \%)$ gonadotroph tumors were positive for GATA3. Diffuse nuclear reactivity was seen in 64 gonadotroph tumors (Fig. 1); whereas, the remaining 4 tumors had variable nuclear reactivity for GATA3.

Eight of nine $(88.8 \%)$ poorly differentiated plurihormonal Pit-1 lineage tumors with variable beta-TSH expression were positive for GATA3 (Fig. 2). While 3 of these were diffusely positive, the remaining six tumors had focal nuclear reactivity.

Two plurihormonal tumors with focal beta-TSH expression also showed focal GATA3 reactivity.

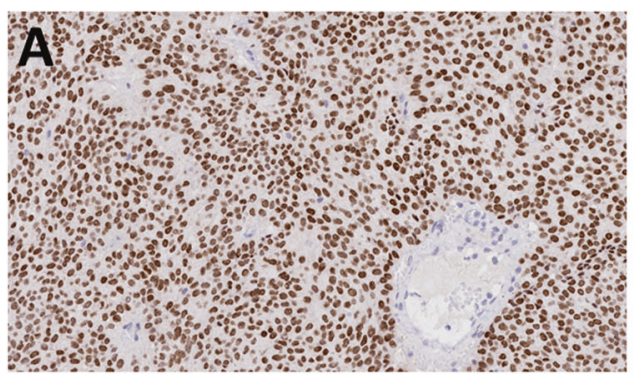

Fig. 1 Immunoreactivity for GATA3 in gonadotroph tumors. Of 69 gonadotroph tumors examined, 64 exhibited strong and diffuse nuclear reactivity for GATA3 a; note the lack of staining in vascular channels.
One of $26(3.8 \%)$ corticotroph tumors was positive for GATA3. This tumor was a sparsely granulated corticotroph tumor. The extent of nuclear GATA3 reactivity was diffuse (Fig. 3). This particular tumor also displayed alpha-subunit expression (Fig. 3) in the absence of Pit-1 and SF-1.

The non-tumorous pituitary adjacent to tumors contained scattered cells that were positive for GATA3; the pattern of staining in serial sections indicated that the GATA3immunoreactive cells were consistent with gonadotrophs, and thyrotrophs, as they were positive for SF-1 or for Pit-1 and beta-TSH.

In addition, the files of the University Health Network identified a metastatic breast carcinoma that presented as a pituitary mass; this tumor was strongly positive for GATA3 and had a distinct appearance from the surrounding nontumorous adenohypophysis that also contained scattered positive cells (Fig. 4).

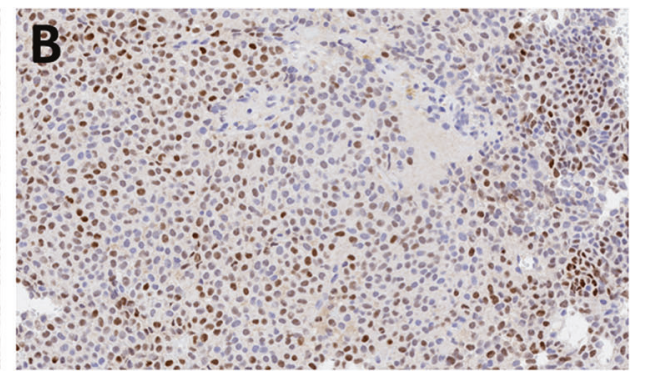

Four of these tumors had focal staining $\mathbf{b}$ and only one was negative for this transcription factor
Fig. 2 Immunoreactivity for GATA3 in a poorly differentiated Pit-1 lineage tumor. These tumors are composed of polygonal cells that can exhibit focal cytoplasmic positivity for growth hormone $\mathbf{a}$ and TSH $\mathbf{b}$ as well as prolactin c; they have diffuse strong nuclear staining for Pit-1 d. This example with TSH positivity exhibits diffuse strong nuclear reactivity for GATA3
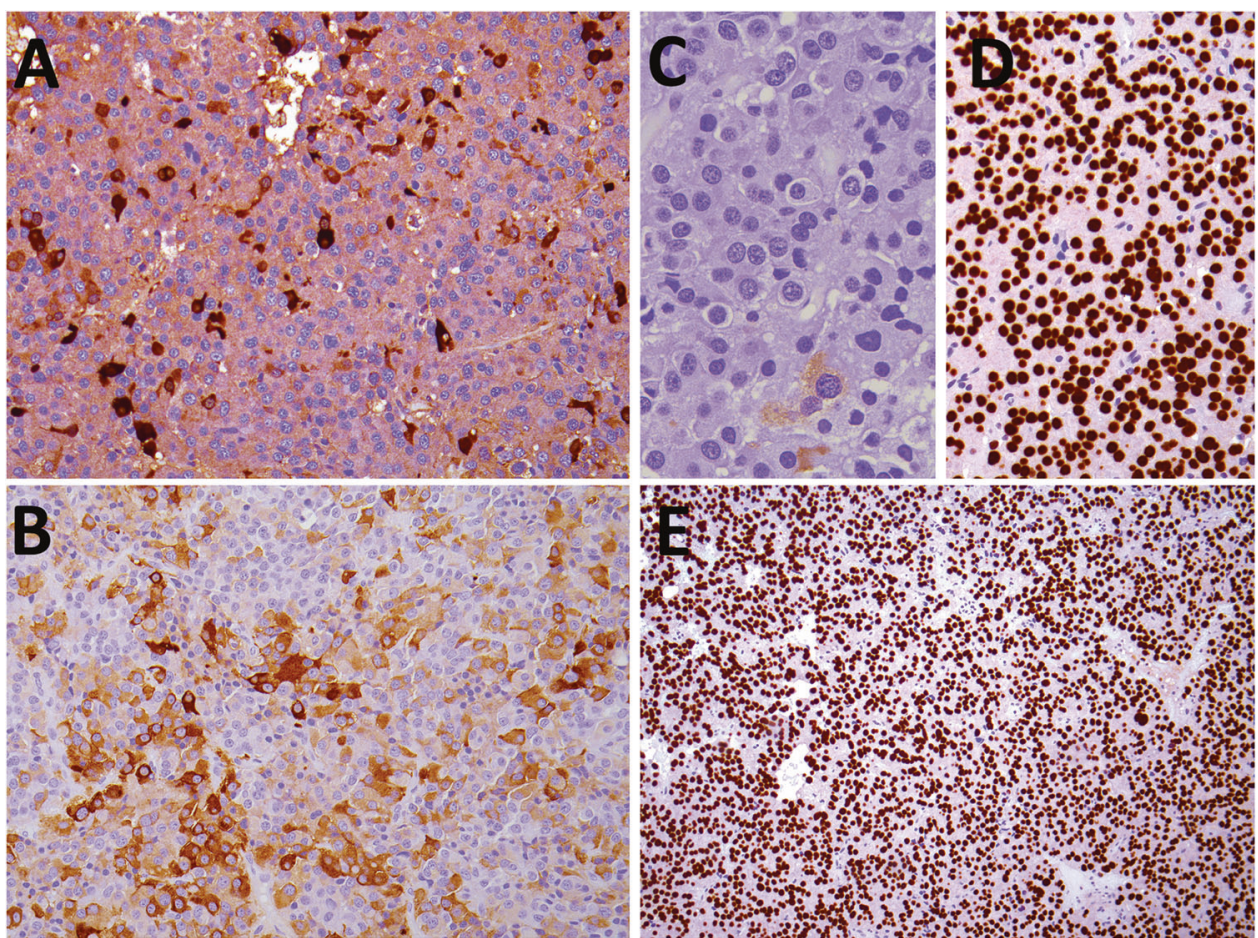

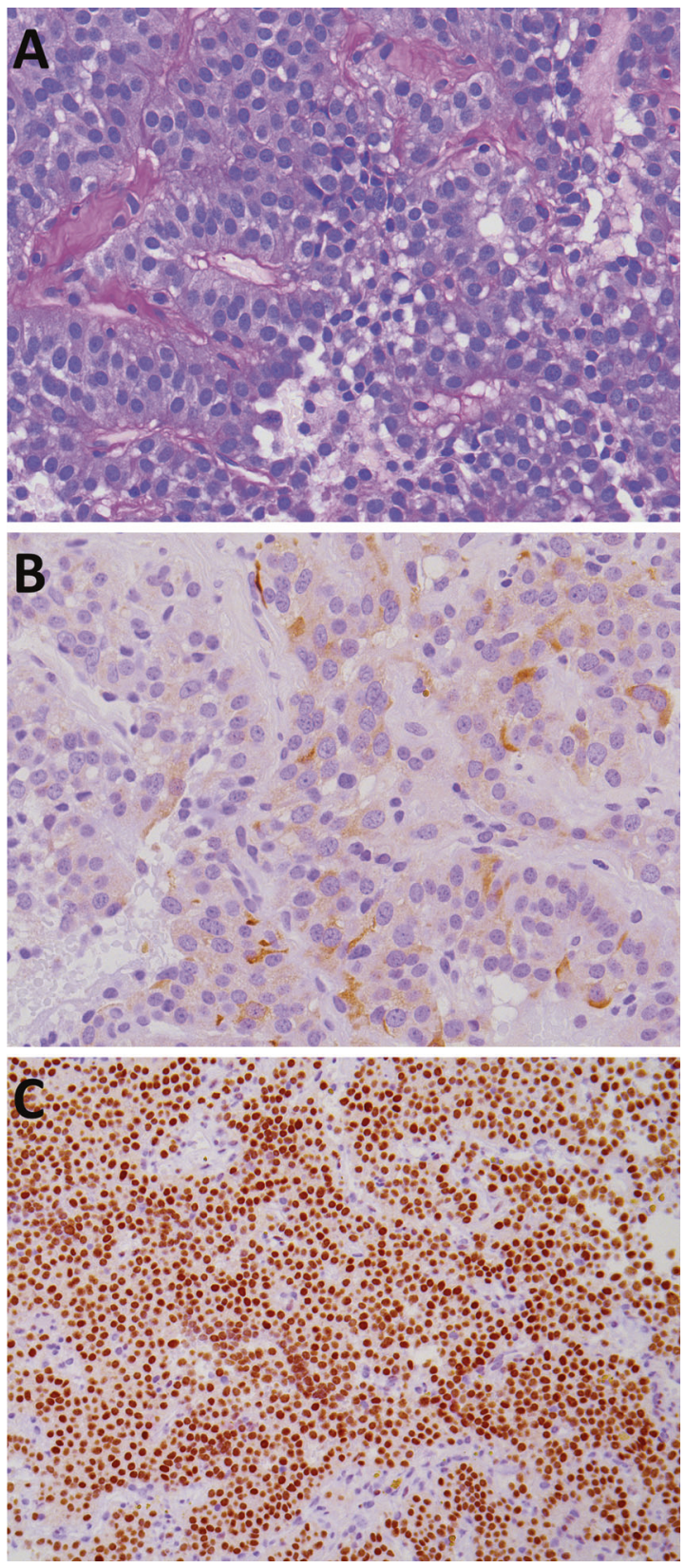

Fig. 3 Immunoreactivity for GATA3 in a corticotroph tumor. This unusual tumor was the only one of 26 corticotroph tumors that was positive for GATA3. It has weak staining with the PAS stain a, consistent with a sparsely granulated phenotype, and there is focal expression of alpha-subunit $\mathbf{b}$, which is unusual in corticotroph tumors. It exhibits diffuse GATA3 nuclear staining

\section{Discussion}

The application of GATA3 immunohistochemistry to the diagnosis of pituitary adenohypophysial tumors adds yet another dimension to this biomarker that has proven to be useful in the diagnosis of urothelial lesions, breast carcinomas, parathyroid tumors, and paragangliomas [20-25]. It is important to be aware of the presence of

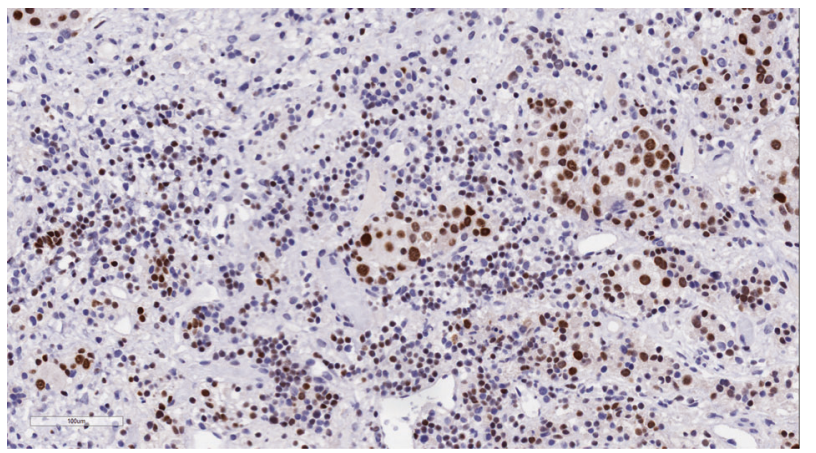

Fig. 4 Immunoreactivity for GATA3 in a metastatic breast carcinoma and surrounding non-tumorous adenohypophysis. This sellar tumor represents metastatic breast carcinoma that is positive for GATA3. Note the surrounding adenohypophysial cells that are much smaller and are composed of a mix of cells that are positive and negative for GATA3

immunoreactivity for GATA3 in lesions that can mimic adenohypophysial tumors. We also report here a case of metastatic breast carcinoma that stained for GATA3 but the morphology and other breast-specific biomarkers can be used to make this distinction.

An important differential diagnosis is paraganglioma. Sellar and parasellar paragangliomas can mimic pituitary adenohypophysial tumors [16]; whereas tyrosine hydroxylase, when positive, can establish that diagnosis, this biomarker is not always positive in parasympathetic paragangliomas located in the head and neck [28]. The presence of S100-positive sustentacular cells is also found in both paragangliomas and adenohypophysial tumors. Keratin positivity is helpful to exclude paraganglioma, but negativity for keratins can be found in a subset of adenohypophysial tumors, especially in gonadotroph and null cell tumors [29]. In the past, most diagnosticians tended to rely on hormone immunohistochemistry, however, lack of hormone reactivity in many adenohypophysial tumors, including a large percentage of gonadotroph tumors [29], and the distinctly more aggressive behavior of true null cell tumors [30] argues for the importance of the appropriate identification of cell lineage of these hormonally inactive but differentiated tumors. The application of stains for other pituitary cell-lineagespecific transcription factors, such as Pit-1 for thyrotrophs, lactotrophs and somatotrophs, SF-1/ER-alpha for gonadotrophs, and Tpit for corticotrophs is required to accurately diagnose the differentiation of an adenohyophysial tumor. This is particularly important in parasellar lesions of the sinuses, as adenohypophysial tumors can arise ectopically $[16,31]$ or can present as nasal masses [32].

A curious finding of this series is the identification of GATA3 immunoreactivity in a single-corticotroph tumor with focal alpha-subunit expression. While the development and differentiation of POMC-producing corticotroph celllineage requires interactions of specific transcription factors, 
including Tpit, NeuroD1, PTX1, and LIF [14, 15], GATA factors have not been reported to play an essential role in this pathway. There are reports of rare corticotroph tumors that express alpha-subunit $[33,34]$ and some of those express GATA2 [34]. It has been proposed that these tumors may originate from ACTH-committed progenitor cells, however, during human embryogenesis, ACTH-positive corticotrophs mature long before the onset of alpha-subunit expression [35], therefore this may also represent transdifferentiation.

The identification of nuclear GATA3 immunoreactivity in pituitary gonadotroph tumors and in tumors that express beta-TSH provides additional support to the classification of adenohypophysial neoplasms based on the transcription factors that determine embryological development. GATA2 is well-known to determine the differentiation of gonadotrophs and thyrotrophs; the identification of GATA3 immunoireactivity in gonadotroph tumors and tumors with beta-TSH expression may be related to the genomic paralogy of or cross-reactivity between GATA2 and GATA3 [19]. Another hypothesis is that a GATA-switch occurs during the cellular differentiation of the adenohypophysial tumor cells [36]; this switch is typically characterized by a change in GATA factor binding to a GATA motif that can potentially host more than one GATA factor, an event that has been reported to occur in both pathological conditions as well as in normal development [36].

\section{Conclusion}

This study shows that the commercially available antibody against GATA3 identifies positivity in adenohypophysial tumors, mainly in gonadotroph tumors and in tumors that express TSH, including poorly differentiated Pit-1 lineage tumors. In addition, we identified GATA3 positivity in one of 26 corticotroph tumors; the significance of this rare event remains to be understood. These results expand the transcription factor expression profiles of pituitary neuroendocrine tumors, and are important in the differential diagnosis of sellar tumors, since GATA3 expression can be identified in primary sellar paragangliomas as well as in other carcinomas that may metastasize to the pituitary.

\section{Compliance with ethical standards}

Conflict of interest The authors declare that they have no conflict of interest.

\section{References}

1. Asa SL, Casar-Borota O, Chanson P, et al. From pituitary adenoma to pituitary neuroendocrine tumor (PitNET): an
International Pituitary Pathology Club proposal. Endocr Relat Cancer. 2017;24:C5-C8.

2. Mangalam HJ, Albert VR, Ingraham HA, et al. A pituitary POU domain protein, Pit-1, activates both growth hormone and prolactin promoters transcriptionally. Genes Dev. 1989;3:946-58.

3. Ingraham HA, Chen $\mathrm{R}$, Mangalam $\mathrm{HJ}$, et al. A tissue-specific transcription factor containing a homeodomain specifies a pituitary phenotype. Cell. 1988;55:519-29.

4. Bodner M, Castrillo J-L, Theill LE, Deerinck T, Ellisman M, Karin M. The pituitary-specific transcription factor GHF-1 is a homeobox-containing protein. Cell. 1988;55:505-18.

5. Bodner M, Karin M. A pituitary-specific trans-acting factor can stimulate transcription from the growth hormone promoter in extracts of nonexpressing cells. Cell. 1987;50:267-75.

6. Yan G, Pan WT, Bancroft C. Thyrotropin-releasing hormone action on the prolactin promotor is mediated by the POU protein Pit-1. Mol Endocrinol. 1991;5:535-41.

7. Li S, Crenshaw EB III, Rawson EJ, Simmons DM, Swanson LW, Rosenfeld MG. Dwarf locus mutants lacking three pituitary cell types result from mutations in the POU-domain gene pit-1. Nature. 1990;347:528-33.

8. Barnhart KM, Mellon PL. The orphan nuclear receptor, steroidogenic factor-1, regulates the glycoprotein hormone alphasubunit gene in pituitary gonadotropes. Mol Endocrinol. 1994;8:878-85.

9. Ingraham HA, Lala DS, Ikeda Y, et al. The nuclear receptor steroidogenic factor 1 acts at multiple levels of the reproductive axis. Genes Dev. 1994;8:2302-12.

10. Asa SL, Puy LA, Lew AM, Sundmark VC, Elsholtz HP. Cell type-specific expression of the pituitary transcription activator Pit1 in the human pituitary and pituitary adenomas. J Clin Endocrinol Metab. 1993;77:1275-80.

11. Asa SL, Bamberger A-M, Cao B, Wong M, Parker KL, Ezzat S. The transcription activator steroidogenic factor- 1 is preferentially expressed in the human pituitary gonadotroph. J Clin Endocrinol Metab. 1996;81:2165-70.

12. Asa SL. Tumors of the pituitary gland. armed forces institute of pathology. Atlas of tumor pathology, Third Series, Fascicle 22, Rosai J editor. Washington, D.C.: Armed Forces Institute of Pathology; 1998.

13. Asa SL, Ezzat S. The cytogenesis and pathogenesis of pituitary adenomas. Endocr Rev. 1998;19:798-827.

14. Lamolet B, Pulichino AM, Lamonerie T, et al. A pituitary cellrestricted $\mathrm{T}$ box factor, Tpit, activates POMC transcription in cooperation with Pitx homeoproteins. Cell. 2001;104:849-59.

15. Pulichino AM, Vallette-Kasic S, Couture C, et al. Human and mouse TPIT gene mutations cause early onset pituitary ACTH deficiency. Genes Dev. 2003;17:711-6.

16. Asa SL. Tumors of the Pituitary Gland. AFIP Atlas of Tumor Pathology, Series 4, Fascicle 15, Silverberg SG editor. MD, USA: ARP press, Silver Spring; 2011.

17. Dasen JS, O'Connell SM, Flynn SE, et al. Reciprocal interactions of Pit1 and GATA2 mediate signaling gradient- induced determination of pituitary cell types. Cell. 1999;97:587-98.

18. Umeoka K, Sanno N, Osamura RY, Teramoto A. Expression of GATA-2 in human pituitary adenomas. Mod Pathol. 2002;15:11-17.

19. Home P, Kumar RP, Ganguly A, et al. Genetic redundancy of GATA factors in the extraembryonic trophoblast lineage ensures the progression of preimplantation and postimplantation mammalian development. Development. 2017;144:876-88.

20. Liu H, Shi J, Wilkerson ML, Lin F. Immunohistochemical evaluation of GATA3 expression in tumors and normal tissues: a useful immunomarker for breast and urothelial carcinomas. Am J Clin Pathol. 2012;138:57-64. 
21. Ordonez NG. Value of GATA3 immunostaining in tumor diagnosis: a review. Adv Anat Pathol. 2013;20:352-60.

22. Miettinen M, McCue PA, Sarlomo-Rikala M, et al. GATA3: a multispecific but potentially useful marker in surgical pathology: a systematic analysis of 2500 epithelial and nonepithelial tumors. Am J Surg Pathol. 2014;38:13-22.

23. Ordonez NG. Value of GATA3 immunostaining in the diagnosis of parathyroid tumors. Appl Immunohistochem Mol Morphol. 2014;22:756-61.

24. Takada N, Hirokawa M, Suzuki A, Higuchi M, Kuma S, Miyauchi A. Diagnostic value of GATA-3 in cytological identification of parathyroid tissues. Endocr J. 2016;63:621-6.

25. Gucer H, Mete O. Positivity for GATA3 and TTF-1 (SPT24), and negativity for monoclonal PAX8 expand the biomarker profile of the solid cell nests of the thyroid gland. Endocr Pathol. 2018;29:49-58.

26. Bates DL, Chen Y, Kim G, Guo L, Chen L. Crystal structures of multiple GATA zinc fingers bound to DNA reveal new insights into DNA recognition and self-association by GATA. J Mol Biol. 2008;381:1292-306.

27. Lowry JA, Atchley WR. Molecular evolution of the GATA family of transcription factors: conservation within the DNA-binding domain. J Mol Evol. 2000;50:103-15.

28. Osinga TE, Korpershoek E, de Krijger RR, et al. Catecholaminesynthesizing enzymes are expressed in parasympathetic head and neck paraganglioma tissue. Neuroendocrinology. 2015;101:289-95.

29. Mete O, Cintosun A, Pressman I, Asa SL. Epidemiology and biomarker profile of pituitary adenohypophysial tumors. Mod Pathol. 2018;31:900-9.
30. Nishioka H, Inoshita N, Mete O, et al. The complementary role of transcription factors in the accurate diagnosis of clinically nonfunctioning pituitary adenomas. Endocr Pathol. 2015;26: 349-55.

31. Thompson LD, Seethala RR, Muller S. Ectopic sphenoid sinus pituitary adenoma (ESSPA) with normal anterior pituitary gland: a clinicopathologic and immunophenotypic study of 32 cases with a comprehensive review of the english literature. Head Neck Pathol. 2012;6:75-100.

32. Hyrcza MD, Ezzat S, Mete O, Asa SL. Pituitary adenomas presenting as sinonasal or nasopharyngeal masses: a case series illustrating potential diagnostic pitfalls. Am J Surg Pathol. 2017;41:525-34.

33. Berg KK, Scheithauer BW, Felix I, et al. Pituitary adenomas that produce adrenocorticotropic hormone and alpha-subunit: clinicopathological, immunohistochemical, ultrastructural, and immunoelectron microscopic studies in nine cases. Neurosurgery. 1990;26:397-403.

34. Suzuki M, Egashira N, Kajiya H, et al. ACTH and alpha-subunit are co-expressed in rare human pituitary corticotroph cell adenomas proposed to originate from ACTH-committed early pituitary progenitor cells. Endocr Pathol. 2008;19:17-26.

35. Asa SL, Kovacs K, Laszlo FA, Domokos I, Ezrin C. Human fetal adenohypophysis. Histologic and immunocytochemical analysis. Neuroendocrinology. 1986;43:308-16.

36. Pihlajoki M, Farkkila A, Soini T, Heikinheimo M, Wilson DB. GATA factors in endocrine neoplasia. Mol Cell Endocrinol. 2016;421:2-17. 